\title{
The mythical structure and bridging of functions A nominal reading in the poetry of KhazalMajidi
}

\section{Riyadh KareemAbdullah ${ }^{1}$}

\author{
${ }^{1}$ Directorate of Thi-Qar Education, Thi-Qar, Iraq.
}

\begin{abstract}
Article History: Received: 11 October 2020; Accepted: 27 December 2020; Published online: 8 February 2021
Abstract: Interconnectednessin the cultural center of the poetic text of Khazaal al-Majidi embodies the actions of the focus of differentiation in employing the myth, and it connects at the other end to the possible rays of what the mythical event is, right up to the poetic dramatization of that event in the text, so that the mythical character becomes the focus of the poet's attention, poetic employment from the point of view of the format implicit represents a formats own culture poet $\mathrm{mm}$ of making the choice myth employee tends to favor the poetic vision of the poet Majidi Although Tmahiaa with methods of recruitment of myth in contemporary poem, making the opening of the text of poetic commonplace and acceptable in the architectural light the modern poem, is not too much that we went to that all the formats that have appeared in this chapter or the next chapters later in the poetry Majidi her mythological roots, identifies with Alostor of mother sometimes approaching, moving away altogether, but the result is orbiting the legend, and draw Its manifestations and existence came from the womb of the myths that lived in the poet's imagination.

Keywords: mythical structure; bridging of functions; nominal reading; poetry of KhazalMajidi
\end{abstract}

\section{Introduction}

\section{Myths are the womb of patterns}

The myth tapestry intertwined from the fields of knowledge, and Evocation means a Sthoudar ((history, religion, knowledge and ethics, they are history because it tells the story of top objects is the subject of reverence and respect ; because it is the origin of everything, which is depending on religion so - as they know because they tell the origin of assets starting from the universe to human institutions ... it is progress through history, religion and knowledge model and, for example, higher behavior and behavior are revived and take it out to the neighborhood $\mathrm{g}$ presence through which to save the myth in word and deed)) [1] , so they are immune to control and selection, views have diverged in defining the concept of one agreed upon myth, e is not that all schoolsIt dealt with the myth analysis and study (Yoheimr) to (Malinowski) to (Levi Strauss) began to look at the concept of the myth of the three principles: the first stems from the fact that the legend describes the historical facts, and the second they represent the symbols of the realities of philosophical permanent, and a it is better reflections of a natural process over its after another Besirorh do not stop [2] .

As well as different approaches in dealing with the myth , including what he sees that the legendary story of the glories of the heroes or Gabrin virtuous, while gold a owners another approach to a Battal mythology natural phenomena have been diagnosed in a his lines promised after that the story of holy figures, while gold curriculum $\hat{\mathrm{A}}$ another that myth story metaphoric hide deeper meanings of culture, dealing a owners symbolic approach with the myth as a symbolic story reflects the whole philosophy of the age, and went a owners mental approach to the emergence of myth as a $\mathrm{n}$ result of a misunderstanding or mistake Group members in their interpretation or reading or storyline of the novel or the incident earlier, the promise of psychoanalysis scholars legendary symbols of the desires of instinctive psychological and emotions, and saw it as a reflection of the desires and a Man repressed off far a from the control of consciousness, so they are full of symbols that we can deep understanding of introduction to the same human desires, and confirms (Eric Fromm) e $\mathrm{n}$ us as soon as we get to understand those symbols opens us a world full of rich knowledge, and sees both (Freud) and his student (Young) that the product of the myth of the unconscious [3].

Malinovsky [4] believes that myth performs a social function in various human societies as it expresses beliefs, deepens and strengthens moral principles, and works to strengthen cohesion within a group, and then supports the members of the group or society and pushes them to participate in building the unconscious mentality. We have reached the structural analysis of a bolder (Demezl and Levi Strauss) that the A Satir structured product of the collective imagination and expression is not a collective feeling, and reveals the connotations and meanings of elements of physical life and psychological own community or a group; Because the common structures contained in the myths of a particular society are in harmony with the inner fabric of the collective mentality of a society or a group [5].

MM A no doubt as to the employment of myth in contemporary poem is ((cultural and artistic vision, in turn , on the other lean cultural references historical and legendary. Ie it is not an individual vision, that her collected in the collective consciousness, Ack 's aesthetically and intellectually for draws from multiple sources of cultural references and a Aad)) [6] , and as the myth constitutes an element of cultural elements ; Because hair is connected to the legend in the first inception contact closely ; So I entered the poetic universe, and formed a 
system of a particular of the structure, and has become a supplier of generous the poets, and provided a for them to benefit from their input a lot of a Vkaarham and feelings investors are in the language of the energies of revelatory and imagination, include poets, their poetry event a Stora a or legendary figure, in order to e Houdar content or significance mythical; To highlight the element of the components included in the emotional experience of modern and poetic [7] and many are studies that proved the existence of meat between myth and poetry in terms of upbringing, function and Walsh all [8], since Monday, stretching to the first roots of history that undoubtedly the late start of human creativity, and this fact makes us rely on the hair in the development of content mythical or, more precisely, that science enriches the understanding of myths u Presentation and vice versa, Valostorh thought and belief, history tells the story of a traditional Introduction Sa of the gods and the like accompanied by religious rituals practiced by ancient peoples, and mum a doubt it that behind all the language of poetry lies a layer of mythological signs and symbols, and precipitates as the first human language in all its embodiment of the passions and feelings spreading life in things.

Perhaps, or for drawing attention to that myth is making the human mind and imagination critic of the e Atali (FICO) when the link between the beauty and history of literary forms, as it believes that there are three stages in the history of mankind are repeated periodically is the stage of the $\hat{A}$ Lhh, stage heroes, and the stage of human beings, and each of these stages distinctive language of expression, as Che first stage that language silent depends on the signals, or loom material have things natural and direct relationship with ideas intended, and is characterized by the language of the second stage as a combination of signals and words spoken and used It contains the relative symbols and images, while the third stage is characterized by modest and agreed-upon words, and humans have absolute control over them [9].

On this goes (FICO) that the language in the first phase and the second was in the original language of the lattice energy the first man of introduction to the private building seeks his world, man has not ignorant but it is a poet by nature. Being possessed the wisdom of poetry inherent determines his responses to the circumstances and formulated Bhaoh poems, symbols, and legend [10], from here realize that myth and poetry spring from one , and that more links between them is an element (fantasy), which doubts for the essence of myth and poetry together and tool identification between them [11], and then lost the myth and poetry in being the product of convergence catalyst and one is a fantasy gushing that shipped awareness, and force the unconscious on the expressive mug on the one hand, and the Nshar with the newly industrialized language in the line of symbolic symmetry from the point of another, thus - Undecided Myth - it becomes a material for the production of literature in the form of the biographies of the supernatural characters that the authors have created and decipher their recipients' codes and incantations by tracing their symbols according to specific philosophies [12].

It seems that the hair ((is the direct descendant of the legend and her son legitimate, has a CT about how the language of the magic that says from without saying, and Chbek sense of without giving a specific meaning or accurate through a message wholeness is detailed)) [13], and this is what he went to Northup Fry in his study of myth, as it tried to link between poetry and myth, returned them the foundation of structural hair, the poet has not only reason enough to create the poem, the poem which owns Walsh all, it is the field of analysis; Because it is mainly a formality reason to look for, and for this reason is the prototype [14].

Led Fry study of myths and epics, to count the basic structure the formation of the capillary is the model of the initial, and become literary works on according to this perception made of other literary works, as it draws the literature of his information and posed by the installation of simple formulas range can be discerned in the initial culture, and see these texts literary In a closed state of rotation around itself [15].

The implication of this the E assumption is made history of literature draws the mystery of his existence and permanence of the literature itself, the overall structures of Assembly sitting in it and be and maintain formats implicit themselves and for the system to survive must remain closed as impervious, do not have an external thing to leak Otherwise, its varieties become distorted and spoiled [16].

From here became the general literature and poetry in particular is the first incubator of the symbol and myth together, and with the development of studies, has become the symbol of cultural and layout of the Mufhomat that defines Dt uses are difficult to be identified in the field of technical employment as ((if everything in the symbol of the universe, and everything is located In the core of the first senses is a symbol that derives its value from the artist's observation of the relationships between the data of the different senses ))[17].

And it was necessary in this case to stand on their references, which grew out of them, as Freud believes that the icon tool in the hands of the unconscious or repressed forgotten, artistic Creativity into Freud 's like a dream while getting out of control in it shall be symbolic images have visible and soles Symbolism is not only a property of dreams, but also a feature of unconscious thinking ( 18 ). Ie the artistic printing is an individual product reflects the depths of creative self - all, be a compound of childhood deposits, traditions and the environment, which remains in the depths of self - reactive and self - contained no obituary called Subconscious [19].

If the subconscious personal is the focus of Freud 's theory, and became the first of the creator and the artist catalyst Astervd it forms and meanings magmatic in self - real - time, which is a nfc v pursuing the artist in every throes of a creative, the (collective unconscious ) is the essence of personal when ( Jung) [20] and he has ((photo of Btdaiah unconscious or psychological deposits of the experiences of Btdaiah unconscious countless, in 
which the ancestors in the ages of primitive, inherited in the tissues of the brain in a way, they are if old basic models central humanitarian experience )) [21].

No longer the awareness of Young framed as Freud, but it is formed in the shadow of a cultural stock heritage extends even human experience with objects and things, and the strength of this stock is designated by Jung ( collective unconscious ) or not to Mcdermatt supreme, those myths and epics driven appeal subconscious (( So it appears in the dreams of individuals and the visions of clairvoyant artists in order to restore balance to the age)) [22] , and these patterns, as Young sees in their essence, are two forms , the higher personal patterns, and the patterns of transformation, and these patterns in their two forms are a human inheritance that emerged from the primitive man's conception of the universe, which is The so-called epics, myths, and the implicit cultural systems that surround them ((where man used to admire strength, tyranny and heroism in all its material and moral colors, and this admiration develops among the generations into a tendency of reverence)) [23].

The genius of artistic creativity inherent in these images and connotations mythological and epic and formatting knowledge that Chuck 's a common denominator between generations, the fact that the epic and myth does not occupy only symbolic because it is rich in mind a fashions typical upper and symbols common, which is as a secret energy orientation of the human imagined, Creativity at Young relies on projection, which is a psychological process by which a person transforms strange scenes in the unconscious into external objects for contemplation of others [24]. This projection is mediated by the cultural system resulting from the intuitive awareness of the creator of the collective unconscious. That is why the creation of the symbol was the greatest function of the unconscious [25], Because ((the best possible truth to express a relatively unknown truth)) [26].

These patterns and their symbols form meaningful structures that stem from the common unconscious, which represents the comprehensive repository of memories and primitive images, inherited from many generations from the ancestors, and the creative artist uses through it a group of semantics that looms from a mysterious distance behind the present experience and affect an invisible influence on the soul [27], It reaches the person to his first roots and remains linked to his land, his gender, and his ancestors, by means of text threads, images and stereotypical connotations [28].

These upper patterns consisting of an unconscious collective, are the legends group and epics that human left by primitive and remained stored in the human mind in different eras and among different peoples whatever the atretic ladder of civilization and civil, according this proposal, man finds himself forced to the reproduction of images The semantics are in similar formulas and this similarity in the cultural systems, and the mythical epic structures between different ages and peoples is the greatest evidence of the existence of the collective unconscious among peoples ((The human soul or the creative power that it possesses absorbs various incentives to produce creative work)) [29], and this is what we find. when Young, who believes that art is the one who explains the artist, not the opposite [30].

The reaction Majidi with myth and tried to restore the capacity of the expressive legends live, labored Fasttmr of the availability of his legendary data in different ways, WaSttaa to enter into the fertile regions, which draws on the creativity and provide him with poetic creation; Because of their ability to giving and giving to meet the need of the poet and provide tools free movement in the threshold of imagination as long as they carry the message that penetrates the time and place the limited, heading towards the absurd and the first land of human encroachment; This hired her in the texts of poetry, through a Stdaa legendary symbol, or legendary story, or the place, but Stora, or simulate the implications, mm of making the texts loaded with lots of signs and symbols, and almost Majidi to be a featured poets of Stdaa these myths and Tozivadtha, was probably not Chtsas the field of ancient history impact of in a Nsyakh behind the act of the legendary, especially believes that ((this legendary includes sacred shipment, which gives the word Gu of a Sttnaiah and link due to the creation and configuration)) [31], has paid this faith to engage in e product (Alostrh) depending where technical technology Jesse Dutt spirit to deal with the myth, and the aesthetic of the legendary production industry, and have carried cultural patterns implicit, tried through it to achieve some of its goals and its objectives And his goals.

\section{Legendary reference and transcriptional connotations}

Was no correlation myth in its early years thinking of human culture, and the extent of the effective capacity of the social to deal with what hampered in the course of his life Balch each optimization that keep the largest possible period of impact in the discovery and interpretation and move the imagination that produces religion and mythology [32], as well as uncle of the suspect has the myth and symbols of vital energy supplies poet ample space graduating from only Nglaq and only Ngmasself down to open up to the human horizon wide, by employing code Balch all the aesthetic best response personalities, events and attitudes and entered in the style of a modern to suggest a contemporary attitude [33] as a system of expressions of symbolic of [34] does not stop at the boundaries of the depth of communication poet self in his experience of life, language , and the degree of belief in their ability to represent and poetic, as far as carrying the Amadmrat systemic transformed into a customary value of a cultural continent, in the mind of the poet and society to some extent both.

\section{- The pattern of the search for immortality}


We find in a group (RuqaiAllnernecat) [35] dimension to the cultural symbolic of Weah in the collective mind of those mediated by signals of a Storah magical atmosphere that trigger an emotional attachment to the cultural convention, as in the poem (paper Adonai) [36], the poet says :

\author{
How our forest ignited and we became \\ We are chasing an amulet like a fairy \\ How did our old date palm fall down? \\ Lord Adonai \\ You were anxious \\ For the immortal .. and whoever created, who created \\ Birds, rivers, and oleander are in paddocks \\ Who tied the hands of hurricanes \\ Whoever splits .. Who splits .. Who splits \\ A seaside and an uproar \\ Your hands shake the water and the spring \\ At night, your eyes are at dusk. [37]
}

Emerges applaud the rebellion done by (Adonai) format interrogative shaded charming showers sensual coming from the depths of the ancient oriental mythology to achieve immortality, and formed an aesthetic manner consistent with its implicit opto and with its culture, no doubt in that all all religions gave to man a kind of immortality before or after death, degrees of this immortality and methods have varied and wove around him a lot of myths that portrayed Aoualemh and formulated its forms, this $\mathrm{P}$ e $\mathrm{n}$ immortality format when human beings doubt obsession for the acquired thinking since the beginning of creation \{ whispered to him the devil said ,' O Adam Is Odlk a mole tree The king does not wear\} [38] and woven many legends about immortality or search for immortality and longevity, including that Luqman a son returned Rabbo asked to give him longevity, it is good among the things including eagle in a Khtar a $\mathrm{n}$ long live the age of seven lancer, was comes a small Balencr of the rears even perish, and so on until six of them perished, was called the seventh (seemed to), and when he grew up and the pyramid was unable to fly and perished sinter and died Luqman. [39] Hence I went some studies that the genesis of the myth as a result of the motives of psychological rights of the old the universe manifestation multiple understanding, and it was the imagination first and his method in the diagnosis of phenomena , became a legend composed of images fictional highly relevant by human psychological and social, so it came ( Ernst Cassirer ) in his research on the civilization of humanity to say: ((That myths, art, religion and language are in fact nothing but pictures, shapes, and symbols, with which a person shapes his feelings and emotions)) [40], and thus constitute a cultural system amenable to many and varied interpretations; Being an important cultural force suspect late in court [41] .

Came symbolic (Adonai) bear the thought of primitive neighborhood of the accomplished poetic Majidi ; They represent the structure of the community have the ability to read the thought of society mediated by the thought of self, and it seems that the discourse on the structure of only Stvham demonstrates collision reality myth in the light of the wastrel glory, and the implicit behind that speech constitutes as a criticism of the human self and awareness of the collective, and call ( Adonai) and turn it into an important part in building the fabric of the speech, to disclose their compressor overshadowed by its effects inherent in society, Msult a light on the culture heritage of rebellion (Adonai) which caused the loss of life, Mstntgaha for the eternal her secret, which is about the loss of immortality and fear From loss and death, and here the pattern plays its role in combining the function of interpretation and assimilation of the human experience on the one hand and the function of influencing and controlling human behavior on the other hand, especially when it is a controlling and dominant pattern [42].

And puts us the poem (The Seal of the Khazal ) in the poetic group ( Eastern Atlas ) in front of the introduction that says ((The locker that Saduri had booze in her jars before the flood )) [43] This introduction returns us to the Epic of Gilgamesh and the story of Saduri, the wine seller who tried to discourage Gilgamesh from continuing His journey to search for immortality, and she informed him of the failure of this journey, which is another picture of (Ishtar and Nammakh), and Saduri said when he met Gilgamesh:

((Where seeks O Gilgamesh / The life you will not find a non / when the created Â Lhh human bone / estimated death on human / accounted for is life)) [44].

In an attempt to discourage Gilgamesh in his search for immortality after the death of Enkido, who realized that the end is death, so he tried to escape death, and on this mythical entrance enters the text an event that opens 
its window on the mythical history as an overpowering implicit value consistent with the poet's perspective and his implicit goals:

\author{
She opens an eyelid and smiles calmly ... her date wine \\ And an apple puts its secrets and its rings in it \\ She bowed his hair and his fingers and gave him \\ Her conclusion but moved away \\ I shouted: Cause diseases or I will throw you from \\ Porch \\ They caused eight illnesses to eight members of Anki Squishy \\ This. \\ The summary of the spring became extinct and the leaves remained dry and it is \\ In her room lying down, crying with pleasure [45]
}

\begin{abstract}
Mimics the poetic discourse and Almmhor cultural epic cover Kalcamh in light of the fact tragedian bitumen modern immortality and the story of the herb, as it conveys the text event movement of Tarikhitth fungal and carries a pattern narrative to describe the collision of reality myth, which thus reveals the dialectic of immortality / yard in human depth, Vegnh to evoke the legendary figures and turning it into an important part carries cash for a humanitarian and awareness of the collective and revealed the most important disadvantages of systemic, highlighting the culture heritage of the death of Enkidu and the loss of Gilgamesh herb that caused the loss of life, Mstntgaha about her secret of a Wellesley who is about loss of immortality and weakness and fear E. Mam death, despite the sense of pride and grandeur, this is not a passed making the pattern of eternity waNksarath represents when the poet coordinated intellectual a cultural a genetic of, here is the implicit Opto to break the usual pattern, it came to pass death of Gilgamesh has not inherited immortality, but a rad poet, the immortality of the soul and the values and principles, this sought in a group ( Khozaial ) in the first book ( the first resurrection of the Bible ) and in a poem (when thrown diurnal such as liver fissured ) open areas She did not set foot, wanting to make his new immortality:
\end{abstract}

The crescent back in the water expels the snow embryos and drops off a muscle On the tin metal, your name would grow in my voice, and a diamond would burn A horse was standing on the heirloom and a twilight came out of my chest and came out

Wine from my tarti and my salt, I said that it was a rain of blood that explodes at dusk The songs and a cursed hour stabs the rose of the face. What is there, a fading green ram in my mind glittering as if you are Sacred knot or ashes? You are hanging in the crater of my dermis counts Blessed by confusion. [46]

The poet as a being linguistically put it that is always being ((when thresholds are open to the metaphors, and to give the presence of sound power, Fattouh, a Alamatah make the most absorption of the search for a corresponding act of Being, and what makes it more able to face the death of a Ntologi, and a sense of terrible annihilation ... poet , the language here is the discourse anti-erase, death and alienation)) [47] Search of the existence of the allegorical, for the super power of salvation and gratification, it moves the present tense within the text strongly, (expelled, falling, grow up, flamed, come out, explode, challenging, shine, hanging, counts) $\mathrm{j}$ inspired the existence of a system of active movement into existence Btgaanha on the course of events to create an imaginary format is intended to reach perfection and immortality, Btamoda image partner of the motor within the personal researcher from the set point ( your name Growing up in my voice ) The impulse is embodied by the speaker (you), the catalyst for the action of (I) in his legendary journey, (twilight comes out of my manly womb, wine comes out of my wave and my salt), which supports that desire to reach the desired perfection, the force of the present-tense verb that suggests the size The movement of the soul and the poet's panting towards eternity: 


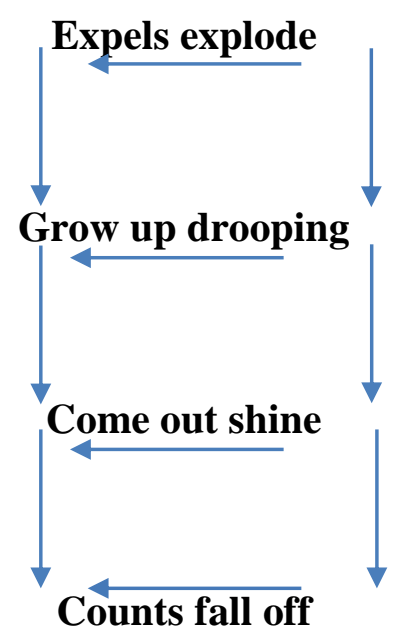

Drilling Majidi text of a Stora by E. Jthad of knowledge in the language, the investor a Alaigaha, and signs and rituals, and dealing with the transcendent object / existent, and with Astihamath or Its blades and Taazimh transmitting the verb imagined in the text and is looking for a perfect picture of poetry for his kingdom which embodies The basic structure of his poetic immortality, especially since the inauguration of his poem itself :

((It was the pride of the harvest and the scent of red wheat, while I compiled an iconostasis of pure fragment.)) [48]

Highlights the rush of the (I) in the text of another of the book itself to show its dominant presence and seek to reach perfection and immortality poetic:

\section{You are then able to deform my pearl \\ And wash my space, so I'll lick your whites \\ Get high by sniffing the nail metal}

And you, who struck your sword, packed the directions and with your insight Leave them to the father of the ignorant, and wait for what you are benefiting from without your astrolabe And your higher games

You play absolutely ... arrange his beads and sticks And they play with the stones of their passing days [49]

The text in his speech, since its first appearance (You are then able) opens a door in which the addressee invests his position in which he announces the direction of the movement to him through the (I) who has highlighted his dominant orientations and steps on the scene of the event: (You are able, the hitter, the benefactor, you play absolutely, arrange bead and Oawadh), described the ( you ) that Walsh all granted sovereignty up to the stage of immortality, and straining himself too much in order to achieve this ; Because it is often that seeks permanence and communicate, but shall be the fate of a Net / the A Na is not only yard unless William evanescent as fade and disappear, while it remains purports to immortality in his travel until his arrival at the final stage , which means the imaginary space wider, which embodies the goal in Neil Glory of Eternity:

\section{$O$ that glory that floats in the field of blood and magnets!}

$O$ the steam that goes out from the neglected sun!

$O$ you and you yearn for water that moistens your tongue, so it falls on crosses

Heavy days and splitting them and get gold!

The black horse of your imagination was spinning and nature was preparing

She held a whip, and the horse's hoop shone

$$
\text { And spin .[50] }
$$

Search continues ( Khozaial ) panting behind the E. Grand Guaouat and Lesser of immortality, in an arduous journey characterized by adventure and challenge to achieve the goal ( to play absolutely) in the kinetic approach 
imagination depends mainly in the act, and begins to travel Almkhiala draw a cultural image that match his own vision and mediated dramatic appeal to the exclamation point ( $\mathrm{O}$ This is glory, oh steam, oh you ) for the purpose of deepening and strengthening that vision, and this had its effect in inaugurating the work of the imagination that made ( glory floats in the field of blood and magnetism ), since ( glory ) can only be reached by adventure and heroic action that challenges and crises are facing, as well as not The (black horse of imagination ) that was spinning can be stopped and will remain to arouse wonder and wonder with its black color and its circular motion which is inconsistent with nature; Because the journey must reach its target specified in the dream area and immortality. And (Khazael) continues his search for immortality and dream, perhaps arriving at some time.

Mixed in ( Eurycomalongifolia Rambo ) biography Rambo biography of the poet, as the text moves in the spirit of a legendary moving between Alsartin to create Gaiaa the building making pattern runs sequentially, and with visions and ideas of cultural and modern new does not stray much of the past pattern real picture of reality by the nature of society, RFID AlsertanBhetwasal construction Gaii within the legendary building falls a narrative format his effectiveness in poetic space:

\section{He pulls the bags of heaven with him, and pulls them with difficulty ... Some force is in History moves poetry into prose and confuses it. \\ His soul appears in the waves of the river, these chalets of the sun \\ He always separated it with his stick, the body his most dangerous stove, the body \\ What a sadness ... fruit hanging outside the orchard. In front of two lips \\ Two clouds and laughter pumping roses in front of a deaf river, and women Expelled from my wellness bending over with bows and adulation \\ And fat, a hand that extends a black light to me, what do I say to all of these Luxurious clothes, his mother wants to rebury his body and finds her yet Ten years of his death bright and powerful, and his name on the grave did not Rust touches it, what should I say to hands traversing light and river? (51)}

The poetic imagination and the formative elements that the poetic language gave her create a scenic image that the narrator conveys, and it is organized in the mythical domain (he drags the bags of heaven, his soul appears in the waves of the river, the chalets of the sun divide it with his stick, a hand extends to me, his mother wants to return his corpse, so she finds it bright and strong, Stitching a light and a river ), then (Rambo) turns into an imagined character who lives on reality and exploits his existence until he reaches the stage in which he becomes immortal. And a place even after his death and his death; Because it is present by the power of his poetic tendency, and perhaps Majidi also realized ((that poetry represents the code of its blades to seek what falls from the rituals of its own magic, as it symbolically symbolizes the decoding of the confusions of the code of his secret spirit herb and its loud propensity for immortality, and perhaps he realized that the poem alone possesses the extraordinary ability to record what The person is obsessed with him, as we find this person's obsessions, traces and signs left in the traces and in talismans, incantations, tablets, and uplifting in the form of signs and symbols completely similar to the nails of hair ..)) [52] This is what the legendary story shows in its narrative action, as if the poet finds him An alternative solution to the universal immortality by mediating the methods of the petty temptations of immortality, so he resorts to resorting to his poetic immortality.

\section{- The pattern of fear and pessimism}

Of the A reasons that drive the poet resort to myth and that when controlled by the cycle of anxiety, but Disturbance and confusion, loss, fear, pessimism, [53] and when this attitude dominates the poet turn to his portrayal in the form of symbols; To express uncle of a capable of signing in mastery, especially since that position related to - of course Alhal- religious and fictional scenarios that grew up in the middle of social, and here went some studies that any attempt to understand the myths and symbols and their interpretation requires from the standpoint of anthropological study and analysis of the elements of building social And the elements of culture as long as society is the one that gives the symbols their meaning, [54] and thus the pattern performs its social function.

Associated with many customs, myths, legends birds since the pre - Islamic era and to this day dominate the layout Belief, and the experience of a social, Azzedine $g$ that the belief that the descriptions of the bird and its specificity was able to the collective mind of the community even became an expression of human ignorant in their own positions of Life and death [55], and for this reason the bird had a strong presence in many myths among the Arabs. Renowned for its privacy without other animals, and these myths associated with certain birds A envisages the crow, the more Arab poet in his poems mention even a crow has been replaced large space in the culture of pre - Islamic era as a some extent motivated fear and doom, but that The Arabs most often view the 
crow: that it is a malicious bird that the Arabs hate to see. Because with them it foretells death and affliction, and the separation of loved ones, and has characteristics that are unique to it without other birds [56].

This was dominated by the modern poet, systemic too, and deal with a new spirit, e y carry visions and a Vkara a Metzj where technical Paljmala and Balamadmropto, and Majidi treated with a his lines and crow absorbed symbols and a Avadha and Touhah of semantics, If we find it in the poetic group (perhaps .. who knows!) From a poem under No. 90, the crow calls:

\section{On the day you left \\ I drove a majestic crow from you \\ He wanted to catch you \\ I was taking away the traps of time \\ And you were taking me away from you [57]}

Is reflected $\mathrm{Z}$ us pattern mediated by a correlation to leave Balgrab and as a $\mathrm{n}$ e existence of eternal relationship and the glue between the crow and leave, and it seems that the pattern crow became a Iconh filled Pfdhaouat desolation and separation in the collective consciousness of Arab culture, and coupled with the crow dimension and leave, so I hate the Arabs see the crow; Because it denotes the dispersal of loved ones and their distancing from their homes, and they called it Babi of doom [58] The word for crow evoked the vocabulary of doom and departure within the text:

\section{On the day you left \\ I drove a majestic crow from you \\ He wanted to catch you \\ I was taking away the traps of time \\ And you were taking me away from you [57]}

In this picture it occupied the crow place a roomy of human thought in the pre - Islamic and belief, and it was his pre - Islamic poetry of great importance; Because he doubted for a basic structure built mental ignorance and ideology, and the human look ignorant crow look legendary calls for the ominous, it is one of the most bird $t \mathrm{t}$ number mentioned in this area, Venaibh predicts the distinction sweethearts [59], until he became they have the code of pessimism and loss, Vetojawa on the departure of a pill at that Antara says:

I expected those who parted, and the Hooded Crow ran between them

The breach of the wing was as if the beard of his head was a gull with the news, fragile, fond of

So I rebelled him from never budding his nest and becoming one to mourn

Those who mourned for me for their parting have watched overnight and are in pain (60)

The crow in the code text of the separation codes when you especially Antar and when most of the poets of the pre - Islamic era in general, and has been a strain of pessimism from the crow of his name they derived their food - goddess, alienation, and they derived his name from the color Gharbab (color of a black). [61] This pattern continued to be effective for other eras. This Umayyad poet Hadba ibn Al-Khashram says:

\section{The crow tells us that our loved ones will shy away. I lost you, $O$ crow [62]}

And continue a envisages an ominous crow among poets because she managed human thought Arab, and operates conscience popular many of departed, caused by the A Satir and anecdotes and explains many of his movements and cantonments interpretations vary by E. Chtlav community environments and cultures, here is a Bo NawasAak d What He precipitated his imagination, saying:

\section{And it is narrated that the raven is hateful to him, for he is the propagandist of the sun [63]}

Doubt for the crow icon for parting and Banshee, which discloses the depth of self - experience and a Sabha of sadness at the parting of a pill, from here carried a envisages the crow a Aad A Chet $\mathrm{Z}$ different connotations and was not parting E. No E Haddaha, was the presence of crow means the presence of death and separation of a Baddi, comes a poem ( crow ) from within the texts ( the sorrows of Iraqi Sunnis ) and the number (365) text has this calendar reflects the epic sadness and a no Iraqi after the E. Anlal of a Merike Iraq and a bloody 
events that Tel T. the E. Anlal, the text of the poem since the threshold of the title Tertsm image of death that a solution in a country poet (Iraq) and the suspect 's legendary structure of the interactive narrative within the text!

\author{
When the crow shouted \\ People gathered around him and waited \\ Graves gathered and small rivers \\ But the crow threw his packet and flew away. \\ No one came forward to open it \\ We waited a long time with the bundle closed between us \\ I went ahead and opened it and saw many eggs hatching young crows \\ And when she spread the navel on the floor \\ Little crows jumped \\ Then it flew with difficulty \\ It hit us, our homes, and our cars, and every collision with him fell \\ So the people were aghast and wandered \\ And every crow ascended from it to the heights \\ Then he went down with a bundle \\ And put it between us. (64)
}

\begin{abstract}
Writes death text e poetic, he puts his concubine and strangeness a Mam diary; In order to put us poet Khaza'alMajidi a Mam writing the death of my hair a, and restore it as the text of Revelation, E. y seems MajidiMstalp a about what Tohmh its code of death portable image film, surrounded by details and a Sarar and Mathologiat, as it emerged the image text from the imagination Arab in the light of the correlation connotations of pessimism A. Mam death that filled into a large of the psychology of the individual that appear mediated by a Ntlaqh text from ((imaginary based on this reality shook the image of the formation that is trying to portray a personal death Oncb teeth in the body of the Iraqi E. that the period of sectarian violence and in particular Baghdad, and (Raven) is only an image of this death, the dark presence that surrounds the community, and the rush of people to him and rally around him, raising panic ( people gathered around him, the graves gathered, small rivers ) in the actual movement Refers to the horror of the event, and its horrific image, then after that, in a state of gloom, the narrator goes to (the navel ) from among the group of those present in a solitary act ( I advanced and opened it ) after waiting for a long time, so that the result of this singular act will be the reproduction and dominance of crows in an intelligent signal Of confirming the act of human relationship and its effects in the reaction perspective, because the opening of this ( the hub ) and make an individual led to the reproduction of the crows and multiply and then keep them, Man and his choice is responsible for the survival of (crows ) or extinction, so $\mathrm{p}$ e $\mathrm{n}$ as a result of the loss of freedom of e selection will led to the proliferation of these creatures alien to our society)) [65], as if the tyranny of those not e is not the inevitable result the surrender of society and submission due to fear and pessimism of the collective response ; Because a single response does not achieve the desired results for the size, strength and tyranny of these people: The earth was filled with crows
\end{abstract}

\title{
The land was filled with crows \\ People fell in the streets and fields And our country became called: \\ The Land of Black .. [66]
}

And it employs the poet color crow black color, ( and became our country called: the country 's black ) Perhaps his wants to confirm that the curse of the crow lies in Soadeh, as if this curse that landed on the crow Fssodt color still move it to people, Vtndhirhm to leave and disperse, and give a sense of Not trusting the meeting again, the image thus subconsciously unites between the feathers of the black raven, and everything that is happening in his native Iraq and diverts between the poet and his country, so everything that separates him from his country becomes black (a raven), so the mask that covers the face of his country becomes a raven (filled The land with ravens), then it became called the country of blackness, thus uniting all the forces of eccentric blackness, to foreshadow separation, dispersion, estrangement and death.

Raven Bostorath and Nsagath up to the death format in the Arab Code, lodged a cultural pattern of the dominant of the collective mind structure, one of the most important tributaries of the interpretation of the phenomena of the universe, so that the pattern which holds the Arab Thought for the crow Soadeh make it assigned a death, and this is what make crow a tag with his lines and sensors open contexts linked to the situation and the emotional atmosphere of psychological for the same : 


\author{
Let's get going with our lives \\ Let's drink from our fresh water \\ Not from your stagnant water in the swamps \\ $O$ crow perched on our present \\ O Caravan, we are upset \\ O past \\ O my placenta \\ O my enemy.)) [67]
}

\begin{abstract}
Associated with systemic crow link of a Wellesley a poet in the mentality of the composition, they present control ( $\mathrm{O}$ crow perched on our present ) also ruled his past ( $\mathrm{O}$ past ), E. NH fate is holding the enemy who can not escape from him he is a Iconh death : (( Thus welding crow over us and killed the media , Dr. Abdul Razzaq al- sleepy professor in the media section)) [68], wherever he solves the crow resolves with murder and death.

And continues Majidi in the investment of the myth of the crow in the Arab imagination to portray us the size of what I did Daesh, a some extent, but remnants Anlal of a Merike Iraq and the scale of devastation and bloodshed and destruction:
\end{abstract}

\title{
They went through a hole in history Poisons of yellow scorpions \\ They are begging in the tents of Samarra \\ A crow swims in their heads \\ A crow flies in front of them \\ Their strings crept into the gates of gold \\ And they hang their molars on the minarets. [69]
}

(Daesh) ( 70 ) These intruders (from a hole in history) on Iraq and strangers for a glance (crow swim in their heads ) evil volatilization of their imagination and a Vkaarham filled ( poisons yellow scorpions), solves death in areas infiltrating them ((Crow fly in front of them / sneak Ckheothm to the gates of gold / pin Odharashm on the pain of minarets), grew tired and turned the earth and the sky to the black piece and bodies filled the streets , understanding of outsiders on the situation of the social and psychological Iraqi society , a individuals (Daesh) and the composition of a social, and their environments, and their experiences, psychological and their construction completely different from the Iraqi product of the environment : -

\author{
Black clouds filled the sky and the tide cooled \\ Two sheep kills one another in the streets and a plague ravages the world \\ Have fun \\ A hail the size of eggs fell on people's heads \\ And the Tigris loads of water and smoke \\ And he threatens Baghdad \\ How many crow will come to this country \\ With a beard, a short dress, and a black jurisprudence book? \\ How many cups of poison will he carry? \\ How many children will he eat? \\ How many servants will they spread for carpets? \\ And they perfumed water for him \\ Stray flocks [71]
}

\begin{abstract}
Tso t poetic texts the depth of the tragedy, and the size of all $\mathrm{m}$, and destruction , and terror brought by the category of e Rhabiyh, which entered Iraq after the E. Anlal of a Merike, E. insatiable Daesh, the organization who has committed the most serious of the three international crimes, namely war crimes, crimes against humanity, genocide, and Aak d that a report issued by the United Nations High Commissioner for human rights [72] in March / March 2015, and adds that these crimes included murder, torture , and E. rape , and E. Stebad
\end{abstract}


sexual, and forced the Religion change and child recruitment. And crimes of mass executions, most notably the ( incident Spyker ) where the organization Daesh of killing between 1,500 to 1,700 students trained at the base of Spyker military Salahuddin province, mid - June 2014, was shot dead, and threw the bodies of some of them in the Tigris River, and others are buried collectively. The killing of detainees ugly ways, including: slaughter by beheading, burning, Alngriv blasting, stoning and shooting dead as well as the abduction of women and trafficked Bossvhn spoils of war. The United Nations report states that in some cases villages have been completely evacuated of their Yazidi residents, and some Yazidi girls and women who managed to escape from ISIS have described themselves as (gifts), because they were sold publicly or handed over to members of ISIS. The report continues to witness their UN mission met heard girls between the ages of six and nine years, screaming for help while being raped in a house used by fighters Daesh, described by a witness how the E. Tnan of sitting fighters laughing when she was two girls teenage Tgtbban in the room desorption a Subject to , this organization has reached Baltouhh surpassed the brutality of predators.

This ambiguous and volatile situation that is controlled by the invaders Transients and murderers who are throwing their death ritual and a Ediologi on the heads of the roads and people, puts the poet a Mam Scarecrows absentee Mtheologiath objects, but they present the $\hat{A} \mathrm{n}$ in (farewell Baghdad ) as they MtalpsonBaktamh war and Scarecrows death daily:

\author{
Death-thirsty killers carry clubs $T$. \\ Swords, knives, pistols and machine guns \\ And they shout at shrines, markets, and hospitals \\ They reject everything even themselves \\ Do you cry Iraq? [73]
}

Text here a quasi What is b (certificate) and existentialism on what he sees, not what you imagine! What he sees as making the size of a not fear a Mam game broken body bigger what endures and defeated E. Wonsan.

Raven was not alone has a Satirh when the Arabs, I've had a bird owls also a Satirh, e y e n Male Album Mythical creatures that employed in Arabic poetry, especially in the pre - Islamic poetry, and of the mythical creatures that employed in the pre - Islamic poetry legend (important or echo ), namely E. ensure that demonstrate something one a male owls, who usually lives in cemeteries, and symbolize the darkness, thirst, and death, a medium between the world of the dead and the world of the living, it is asking for revenge, and tell the dead what shall be after his death, and was the Arabs You look at the owls as a doom bird, and you feel bad about it and are alienated from its sound [74].

The invited poets Gahleon legend mentioned album / important in two very close together, some of them tens of and in the context of incitement to a take revenge and not to accept blood money, while tens of her other Wen in the context of the lament of the Dead is not killed, to show the state of lament on him and on his days and his gifts or bemoaning the courage and so [75], and this is a finger aggressive Aoz in a significant his lines through the threat to a cousin of his age to kill him if he did not stop insulting and cursing, so make important crying on his grave asking revenge to him:

\title{
O Amr, do not let my insults and my insults strike you, where the important says: Water me [76]
}

And this deep accumulation of the myth of the important and the echo and the owl, which was consumed by Al-Majidi, evokes the symbolism of the legendary owl in his poem ( 5 August | I am looking for it in the lower world ) saying:

\section{One day, the earth will open up to me from a grave I will enter it satisfied I will ask about my son there \\ I will search for it in the lower world \\ I will search for it in the lower world \\ I will not let the owl hide it from me \\ I will not let the long beards of the priests cloud him \\ I won't let fish eyes catch him away. [77]}

Shows album as symbol of darkness, and kidnappings, and death ( the earth will open up to me about the grave of one day ) the grave Bzlmth and (Owl obscured by me ) which suffer for E. kidnapping his son Marwan by Daesh gangs and the pain of loss, and this made him restless in his studio linguistic / The e Stara and a 
Icona , Vtelm Q the way to the poem and perhaps his seeks through refuge and spared from the aches and Alfoadja- and a j tragedy and calamity the greatest and a hit of tragedy has turned Alabn- myths to restore the myth of the Holy death Son's death. E $\mathrm{n}$ after the death of his son Marwan lives continue to make ((with elements that can be done with it in the real world continues, but the psychological attitude or feeling is the compressor that forces the poet to use this not a sloop)) [78] without others, E. y entered the underworld and deal with him, and that was transformed E. positively of the Mq of anybody as long depth of the tragedy, the tragedy of lost son in the sense Mq of anybody as long loss to go down to the lower world teleconverter a Subject to the a RIP to open his tomb and The question then for his son, not to leave important calls for a Sagona It thus creates a paradox with systemic a envisages owl / important.

The Aoz P poet Album bird in his poem ( Avrchi Shall when my bed ) that single - handedly Eptdiha death, saying : (( the image of death which transcends sex, drink and sleep )) [79]

And he concludes the poem by saying: -

\section{Owls with their nails and their obscure ancient wisdom fold our hands And all together (me, you, and owls) But the ends close and the tears increase. [80]}

Written death since the threshold Anoanah poem Baahaiha Spatial ( Avrchi Shall when clinical ) leading to what can be Aters Meh poet from the worlds configuration to die if a $n$ throws his body on the bed, image of death haunted as haunted by crowds of the memories that provoke the endings, Vtdfh to maximum dates by language, the charming power that is drawn through Astaradtha and Mjazatha and blades and Sdmadtha to what can Aab $t$ about his inner voice deep immersion in the metaphors of the call, and Visage cleansing, it seems everything is Nags but endings have brought the owls present old in his wisdom, folding Our page in life because it is a symbol of death.

\section{CONCLUSION}

We find that the interconnectedness in the cultural center of the poetic text of Khazaal al-Majidi embodies the actions of the focus of differentiation in employing the myth, and it connects at the other end to the possible rays of what the mythical event is, right up to the poetic dramatization of that event in the text, so that the mythical character becomes the focus of the poet's attention, poetic employment from the point of view of the format implicit represents a formats own culture poet mm of making the choice myth employee tends to favor the poetic vision of the poet Majidi Although Tmahiaa with methods of recruitment of myth in contemporary poem, making the opening of the text of poetic commonplace and acceptable in the architectural light the modern poem , is not too much that we went to that all the formats that have appeared in this chapter or the next chapters later in the poetry Majidi her mythological roots, identifies with Alostor of mother sometimes approaching, moving away altogether, but the result is orbiting the legend, and draw Its manifestations and existence came from the womb of the myths that lived in the poet's imagination.

\section{References}

A. Mohammad paste : Encyclopedia of legends of the Arabs from ignorance and Dalalaltha, Dar Al - Farabi, Beirut, i 1, $1994 \mathrm{~m}$ : c 1.35.

B. Sayed El- Qimni : Myth and Heritage , The Egyptian Center for Civilization Research , Cairo, 3rd Edition, 1999 AD : 33 .

C. Bronislaw Kasper Malinowski : (1884-1942), a world Polish specialist in the science of human , and is the most important scientists of human in the century, the twentieth, which is the most important pioneers in the science of human applied.

D. Alex Micilli : identity, translation d . Ali Watfa, French Publishing House, Damascus, 1st Edition , 1993 AD : 66.

E. Muhammad Abd al- Rahman Yunus : theoretical approaches to myth, its importance, and its use in poetic discourse , http://www.averroesuniversity.org/pages/myounis05a.pdf

F. Ali AshryZayed : Recalling the Heritage Personalities : 175. And see : Ali Abdel Moati Al Batal : The Mythical Symbol in the Poetry of Al Sayyab, The African Library, Cairo, 3rd Edition , 1975 AD : 72.

G. Ahmed Ismail al - Naimi : Myth in the Poetry Arab before Islam, , Dar affairs Cultural Public Baghdad, i 5, $2000 \mathrm{~m}: 8$.

H. Ferial Jubouri : approach the legendary comparative, magazine chapters, vol 1, p 3, $1981 \mathrm{~m}: 106$.

I. Hcz, trans : structural and flag signal, T Rajmah : Majid Almactp, Review : d . Nasser solution of Wei , Dar affairs cultural public, Baghdad , (d . I ), $1986 \mathrm{~m}: 9$.

J. Herbert Reed : Art and Society, T. Rajmah : Fares metric, Dar pen, Beirut , i 1, 1975 m : 97.

K. Abd Allah bin OrhanAtawi : receiving pendants - study in the reception cascade, the world of books to 
talk, i 1, $2013 \mathrm{~m}: 451$.

L. Feras Al- Sawah : Myth and Meaning - A Study in Mythology and Eastern Religions, Dar Ala Al - Din , Damascus, 2nd Edition, $2001 \mathrm{AD}: 22$.

M. William K . And Klint Brooks, criticism of literary : the history of a summary of the criticism of the modern , T. Rajmah : Hussam Al - Khatib and Mohi - Din Sobhi , the University of Damascus , $1976 \mathrm{~m}$ : 206.

N. Terry Evelton : the theory of literature, translation : Thaer Dib , publication of the Ministry of Culture of the Syrian, ( d . I ), $1985 \mathrm{~m}: 162$.

O. Muhammad Fattouh Ahmed : Symbol and Symbolism in Contemporary Poetry, Dar Al Maaref, 2nd Edition, 1978 AD : 112 .

P. Alexander Ro_ka, creativity public and private, T. Rajmah : Ghassan Abdul neighborhood Abu pride , a series of world knowledge - 144 , Kuwait , $1989 \mathrm{~m}: 24$.

Q. Muhammad Othman Nagati : In Modern Criticism - A Study in Modern Critical Schools , Dar AlShorouk, Kuwait, 3rd Edition, 1998 AD : 186.

R. Carlustaf Young (1961) : Dr. diseases Mindset, the world Saikolǫaa , and philosopher Swiss great, his School in science psychology, schooled at the hands of Sigmund Freud, interested in Balmithologia and linked his theories in science psychology.

S. Stanley Hyman : criticism of literary and schools modern, translation, Ihsan Abbas, Muhammad Yusuf Najm, Beirut , House of Culture, ( d . I ), $1958 \mathrm{~m}:$ 245-246.

T. Abdul Fattah Mohammed Ahmed : Curriculum legendary in the interpretation of poetry ignorant - study of cash, Dar Manholes, i 1, $1987 \mathrm{~m}: 23$.

U. Anas da d : Legend in the poetry of the Arab modern, library Ain Shams, Cairo , ( d . I ), 1975 m : 24-25

V. Abdul Fattah Mohammed Ahmed : Curriculum legendary in the interpretation of poetry ignorant : 17.

W. Mustafa Suef : the foundations of psychological for creativity art in poetry special , Dar Knowledge , Egypt, i 3, 1969 m : 206.

X. Naeem Al-Yafi : The Evolution of the Artistic Image in Modern Poetry, Arab Writers Union Press, Syria, 1st Edition, 1983 AD : 285 .

Y. Abdel Fattah Mohamed Ahmed : Curriculum legendary in the interpretation of poetry ignorant $: 84$.

Z. Saad Hassoun Al-Anbaki : Pre-Islamic Poetry : A Study of Its Technical and Psychological Interpretations , Dar Tigris , 1st Edition, 2007 AD : 157 .

AA. Karen Armstrong : A History of Myth , translated by : WajihQansu, The Arab House for Sciences, Publishers , 1st Edition, 2008 AD : 8 .

BB. Muhammad Fattouh Ahmed : Symbol and Symbolism in Contemporary Poetry, Dar Al Maarif, 2nd Edition, 1978 AD : 288

CC. FarajYasin : patterns of personal Almastrh in the story of the Iraqi modern, Ministry of Culture, Dar Affairs cultural public , Baghdad , i 1, $2010 \mathrm{~m}: 49$.

DD. Allnernecat represent a form of magical texts when the Arabs, Khaza'alMajidi : Business noodles , c 2: 904 .

EE. Sheikh Kamal Al - Din Al - Damiri : The Life of the Great Animal, Al-Alami Foundation, Beirut, 1st Edition, 2003 AD , Part $2: 35$. And my eyes : the story of Luqman and Nsorh within the story of Hood in the Brides councils : Thaalbi ( Abu IshaqThaalbi ) : Dar thought Islamic for printing and publishing, Damascus , ( d I . V ) : 52-53.

FF. Muhammad way, and Abdul Salam Benabd high : nature and culture, Dar Toubkal , i 1, $1991 \mathrm{~m}: 25$.

GG. Karem Mahmoud Aziz : Myths of the Ancient World, Al- Nafez Library, 1st Edition , 2007 AD : 21.

HH. Umniah Muhammad Ali Nawar al-Masri : The Aesthetics of Symbolism in the Arts of Modernity and Postmodernity, a Comparative Critical Study .. Master Thesis, Faculty of Education, Helwan University, 2004 AD 34.

II. Viewed : Firas Tourists : Encyclopedia of the history of religions, Egypt, Syria, the country of Mesopotamia, the Arabs before Islam, Dar Alaa El Din , i 2, 2007 m , c 2: 272 , seen : TahaBaqer : Epic of Gilgamesh, the Republic of Iraq, Ministry of Culture and Information, Dar Al-Rasheed Publishing, 4th Edition, 1980 AD : 135 .

JJ. Ali Hassan Al - Fawaz : Khazal Al-Majidi ... The Absentee Shirt and Restoring the Vision , Al Mada Newspaper , Issue (3311 ), 3/14/2015 https: //www.almadapaper .

KK. Ali Hassan al - Fawaz : Khaza'alMajidi .. shirt absent and restore vision , newspaper term , number (3311 ), 14.03.2015 m. https: //www.almadapaper.

LL. Abdel - MoneimTalimh : Introduction to the Theory of Literature , House of Culture Printing and Publishing, Cairo, ( d . I ), $1973: 81$.

MM. Ahmed Abu Zeid : symbol and myth in building social, magazine world thought, volume 16 , number 3 , Kuwait, December 1985 AD . 
NN. Abd al - Qadir al - Ribai : The Bird in Pre-Islamic Poetry, The Arab Foundation for Printing and Publishing, Beirut, 1st Edition, 1988 AD : 27.

OO. Hamad bin Ali bin Hamad al-Faqih al-Husayni al-Hashemi : Addressing birds in Arabic poetry until the end of the fifth century AH, master's thesis in literature and criticism, Umm Al-Qura University, College of the Arabic Language, Kingdom of Saudi Arabia, 1435 AH - 2014 AD : 26-33.

PP. Abdul Salam Mohammed Haroun, Beirut , ( d . I ), 1969 m , c 2: 317. seen : Mohammed bin Musa bin Isa bin Ali Demeiri Abu stay Kamal Din El - Shafei , big animal life , house books scientific, Beirut , i 2 , 1424 e c $2: 172$.

QQ. KhatibTabrizi : Explanation of Diwan Antara , , presented to him and put its margins and their indexes glorious cruiser, Beirut, Dar thought Arab, i 1, 1412 AH / 1992 AD : 94.

RR. Al-Jahiz : the animal, Part 3: 147. And seen : Muhammad ibn Ishaq al - Baghdadi Yacoubi : the history of Yacoubi , commented on it and put footnotes : Khalil Al - Mansour, Dar books of scientific , Beirut, $\mathrm{i}$ 1, 1419 e 1999 - m : 16. and seen : Thaalbi ( Abu Mansoor Abdul King bin Mohammed , 429 e ): representation and lecture, achieve : Abdul Falah Mohammed sweet, Casablanca Arab book , ( d . i ), 1983 m : 458. seen : Kamal Din Muhammad ibn Musa, Demeiri : the life of the animal major, Press Interlace cycle, then, i $1,1425 \mathrm{H}$ : c 2:13. And seen : Mr. Mahmoud ShukriAlusi : attaining Alorb in knowing the conditions of the Arabs, me explaining and corrected : Mohammed delight Archaeological, House books and scientific, Beirut, i 2 , ( d . V ): c 2: 334-336. And seen : Ali Abdul Aziz Ali Abu Sunaina : The crow in poetry pre - Islamic, Master Thesis, An- Najah National University, Nablus, Palestine 2012: 6. seen : bigeye, animal, c $2: 316$.

SS. Poetry Hadba Ben Khashram, collection : d . Yahya Al - Jubouri, Publisher : Dar Al- Qalam, Kuwait, Edition 2, $1406 \mathrm{AH} / 1986 \mathrm{AD}: 36$.

TT. Diwan Abi Nawas : achieve : Elijah h of Wei, Publisher : Company World Book, ( d . I ), 1987 m : 63.

UU. Abdul Qadir bin Omar al - Baghdadi : wardrobe literature spiral door tongue Arabs achieve : Abdul Salam Mohamed Haroun, Dar book Arab, Cairo, ( d . I ), 1967 m , c 1: 316. seen : Mohammad paste , Encyclopedia of Legends Arabs On the Jahiliyyah and its Implications : 335 .

VV.Wahab Romans : employ the myth in poetry pre - Islamic , Journal of Heritage Arab magazine quarterly issue of the Union of the book Arabs - Damascus No. 93 and 94 - year fourth and twenty - March and June 2004 AD . And see : Hamad bin Ali bin Hamad al - Faqih al- Husayni al - Hashemi : Addressing birds in Arabic poetry until the end of the fifth century AH : 55 .

WW. See : Abd al - Qadir bin Omar al-Baghdadi : the treasury of literature and the core of the door of the tongue of the Arabs, Part 7: 184.

XX. Moses Rababa'a : aesthetics and style of receiving, applied studies, Hamada Foundation Studies University Wa for publication and distribution, Irbid , i $1.2000 \mathrm{~m}: 69$ 